\title{
Estigmas territoriales y distinciones sociales: Configuraciones espaciales en la ciudad de Medellín
}

\author{
al \\ Natalia Quiceno Toro* \\ Paula Sanín Naranjo \\ Recibido: 17 de abril de 2009 \\ Aceptado: 30 de abril de 2009
}

\begin{abstract}
RESUMEN
Este artículo es Resultado del proyecto de investigación Narraciones del Espacio y construcción social de "lo popular" en Medellín, desarrollado durante el año 2005 en el marco del grupo de investigación Cultura, Violencia y Territorio del Instituto de Estudios Regionales INER, Universidad de Antioquia. Las distinciones sociales están presentes en las formas como habitamos la ciudad, en los lugares elegidos y los excluidos en nuestros recorridos cotidianos, en las imágenes y estigmas que construimos de los "otros" que viven en esos lugares y en los lugares mismos. En la ciudad de Medellín la segregación socioeconómica es un rasgo visible en la geografía y en el ordenamiento territorial. Sin embargo, esa segregación también es visible en el nivel de los imaginarios y prácticas que se ponen en escena en las formas como habitamos la ciudad, en este caso la forma como un grupo de jóvenes de diversos estratos habitan Medellín. En este artículo nos acercamos a la configuración de estereotipos y estigmas sobre el "otro" cercano y el espacio que habita y a la manera como se conforma una geografía de la alteridad en la ciudad.
\end{abstract}

Palabras clave: Distinciones Sociales, Estereotipos, Estigmas, Segregación, Medellín.

\footnotetext{
Antropóloga. Magíster en Ciencia Política y coordinadora del grupo "Cultura, violencia y territorio. Universidad de Antioquia. Dirección electrónica: nquiceno@iner.udea.edu.co

Antropóloga. Dirección electrónica: psanin@iner.udea.edu.co.
} 


\title{
Territorial Stigmas and Social Differences: Spatial Configurations in Medellin City
}

\begin{abstract}
This article shows the results of a research called: "Narrations of Space and Social Construction of "what is popular" in Medelllin," conducted in year 2005 by the Research Group "Culture, Violence, and Territory" of Universidad de Antioquia INER (Instituto de Estudios Regionales).

Social differences are identified in the way how we inhabit the city, in places chosen and excluded in our daily life, in images and stigmas we create about "the others" who live in those places, and in the places themselves.

In Medellín, socioeconomic segregation is an evident fact in both geography and urban planning. Nonetheless, such segregation is also evident on the field of images and practices regarding the way how we inhabit the city; in this case, the way how a group of youngsters from different social classes inhabit Medellín. This paper is an approach to the construction of stereotypes and stigmas about "the other" and his space, and the way how "geography of otherness" is built in the city.
\end{abstract}

Key words: Social differences, stereotypes, stigmas, segregation, Medellin. 
En la ciudad vivida cotidianamente, emitimos juicios sobre los lugares que visitamos y los que no nos atrevemos a visitar. Este hecho, que podría parecer muy simple y natural, fue una de las principales motivaciones para preguntarnos sobre las formas como las imágenes que tenemos de los "otros", extraños o cercanos en nuestra ciudad, nos están definiendo mapas de ciudad y rutas para seguir o evitar determinados lugares. Todo esto, no sólo como una forma de experimentar un espacio particular sino como una forma de construir nuestras relaciones sociales. Es decir, de la proximidad o lejanía con los "otros" que habitan un mismo espacio; desde la diferenciación del "otro" a partir del sentido de la distinción social (Bourdieu, 1998). La pregunta que nos sirvió como carta de navegación en las cotidianidades de, aproximadamente, 70 jóvenes de la ciudad de Medellín fue ¿Cómo nuestras experiencias, en el habitar la ciudad, configuran y reflejan distinciones sociales?

Tres colegios de diferentes estratos socioeconómicos y diferentes sectores de la ciudad fueron el escenario para realizar el trabajo de campo. En el primero, la institución "Gente Unida Luz de Oriente" ubicada en el sector de La Honda del barrio La Cruz, trabajamos con jóvenes de grado noveno, entre los 15 y los 20 años de edad; la mayoría de estos jóvenes son provenientes de otras regiones de Antioquia e incluso de Colombia; muchos fueron desplazados por la guerra y la mayoría han vivido el desplazamiento intra-urbano, es decir, se han movilizado por diferentes barrios de la ciudad, al ritmo de la intensificación del conflicto urbano en ciertas zonas. El segundo colegio fue el "INEM José Félix Restrepo", institución educativa seleccionada como el lugar donde podríamos encontrar jóvenes de diversas zonas de la ciudad y de diferentes estratos sociales. Allí trabajamos con un grupo de aproximadamente 35 jóvenes habitantes de barrios como Castilla, Belén, Santa Fe, Campo Valdés, Aranjuez, El Centro, Robledo, Belalcázar, Pedregal e, incluso, otros municipios del área metropolitana como Envigado, Bello e Itagüí. La tercera institución fue el "Colegio Waldorf Isolda Echavarría", elegida principalmente por el carácter privado y por el hecho que sus estudiantes provienen de estratos socioeconómicos altos; pero también nos interesó su enfoque pedagógico Waldorf,' que la diferencia de otros colegios privados en la ciudad, menos abiertos a este tipo de proyectos. Esta característica del colegio permitió, de alguna manera, la receptividad frente al proyecto.

Este artículo constituye, entonces, un acercamiento a los resultados del trabajo llevado a cabo con los grupos de jóvenes de estas tres instituciones. ${ }^{2}$ Inicia con una mirada general al tema de las distinciones sociales y el estigma territorial para, posteriormente, conocer algunas de las imágenes y relatos sobre la ciudad que los jóvenes construyen en su habitar cotidiano. Finalmente, propone unas reflexiones sobre el papel del estigma y el estereotipo en las maneras de pensar y habitar la ciudad.

Partimos de dos ejes analíticos que permiten pensar la relación entre habitar un espacio, las percepciones y las recreaciones que los sujetos construyen de este espacio (físico y social) y de sus habitantes. Estos ejes son: distinción y espacio social y estereotipos y estigmas. ${ }^{3}$

1 Esta metodología plantea "la educación como un desarrollo hacia la libertad individual, incorporando la expresión artística como un medio de aprendizaje en las materias curriculares. El canto, la música o la pintura no sólo tienen sus clases especiales sino que también se la utiliza en las de matemática, lengua o ciencias sociales para incorporar conocimientos específicos. Además, los chicos participan en clases y talleres de distintos oficios, como carpintería, cocina, tejido y jardinería, entre otros". En: www.revistaplanetario.com.ar

2 Resultado del proyecto de investigación "Narraciones del espacio y construcción social de "lo popular" en Medellín", desarrollado durante el año 2005 en el marco del grupo de investigación Cultura, Violencia y Territorio del Instituto de Estudios Regionales INER, Universidad de Antioquia.

3 Ver Informe Final: Habitar la ciudad: Jóvenes y distinciones sociales en Medellín. INER-CODI, 2005. Universidad de Antioquia. 


\section{DISTINCIONES Y ESPACIO SOCIAL}

Hablar de distinciones sociales es hablar de posicionamientos sociales. Es decir, son las diferenciaciones que los sujetos hacen de sí mismos frente a unos "otros" en un espacio social determinado. Es volver al constante problema antropológico de la identidad y la alteridad. No obstante, la perspectiva de pensar las formas de distinción o los procesos y criterios de posicionamiento en un espacio social dado constituye un lente interesante para leer, desde un sentido ante todo relacional y político, estos temas anclados en la tradición antropológica. Así, el enfoque del que partimos consiste en pensar el trasfondo político de esa diversidad -que cohabita en la ciudad-y comprender cómo ésta enfrenta desencuentros, exclusiones, segregaciones, estigmas, en suma, desigualdades.

El tema de las distinciones sociales lo abordamos desde la pregunta por el habitar, ${ }^{4}$ acogiéndonos al planteamiento de Bourdieu quien afirma que "existir en un espacio, ser un punto, un individuo en un espacio, significa diferir, ser diferente", y conlleva a una exclusión mutua entre los sujetos (Bourdieu, 1999, 121). Entendemos, pues, el habitar como una experiencia que no solamente consiste en estar en un espacio, sino también en desplegar en ese "estar en el espacio" toda una competencia social y cultural, un conocimiento y una memoria que le permiten a un sujeto apropiarse y/o interactuar con otros en ese espacio. El habitar es, entonces, ante todo, una práctica social.

A partir de estas reflexiones, nos preguntamos: ¿cuáles son las lógicas y los signos distintivos que configuran ciertos órdenes de posicionamiento en la ciudad?, ¿cómo incorporamos ciertos condicionamientos para el habitar?, y ¿qué lugar tiene la alteridad en esos condicionamientos? Nuestro

4 Para ampliar este tema ver capítulo I "Habitar: espacios, cuerpos y relatos". del Informe final de investigación Habitar la ciudad: Jóvenes y Distinciones Sociales en Medellín. INERCODI, 2005. Universidad de Antioquia. interés consiste en analizar cómo las diferencias se convierten en criterios de distinción social y cómo esos criterios también tienen una expresión espacial, es decir, propician un encuentro con esa geopolítica ${ }^{5}$ de la ciudad, donde se tejen con esos "otros" juegos de visibilidad, exclusión, segregación y reconocimiento.

En suma, analizar el tema de la distinción nos lleva a pensar, por un lado, su relación con el habitar y por consiguiente con el espacio, y por otro lado, cómo en los procesos de distinción se crea un juego de categorías que se convierten en estereotipos y, finalmente, en naturalizaciones que estructuran un orden de posiciones de los grupos y sujetos en el espacio social.

En el desarrollo de la investigación identificamos dos niveles que fueron centrales para pensar el tema del habitar y su relación con la distinción: la alteridad social y la alteridad espacial. Cuando pensamos a un ser humano o un espacio como "otro" se está estableciendo una relación desde la distancia social, es decir, desde el extrañamiento con lo ajeno, lo diferente. En este sentido, en el análisis de las experiencias del habitar compartidas con los jóvenes, fue central el proceso de cómo la diferenciación de "otros" sujetos conlleva a la diferenciación de "otros" espacios. Se da, pues, una configuración del espacio también desde la alteridad, que se hace visible en los relatos que nos permiten o restringen ciertos andares y en los andares mismos que diseñan unas rutas e itinerarios en la ciudad (De Certeau, 2000).

Estos relatos, como veremos más adelante, nos permiten entender cómo a través de las relaciones que establecemos con los "otros" en la ciudad, les asignamos unos espacios particulares. En el momento en que nos distinguimos de "otro", lo ubicamos a él y por ende, a nosotros mismos,

5 Entendemos como geopolítica de la ciudad a las formas como en el espacio físico se configura un correlato de las distancias y diferenciaciones, jerarquías y exclusiones propias del espacio social (Bourdieu, 1999b). 
no sólo en el espacio social, sino también en el espacio físico. Así, los lugares asignados a esos "otros" nos van definiendo unas geografías de la alteridad y van tejiendo con el espacio unos estereotipos y estigmas con los que identificamos determinadas zonas, barrios e incluso a la ciudad en su conjunto. Esto nos lleva a nuestro segundo eje de análisis.

\section{ESTEREOTIPOS Y ESTIGMAS ${ }^{6}$}

Al analizar las formas como definimos a los "otros" y nos acercamos o alejamos de ellos en nuestros recorridos cotidianos, encontramos que nociones generalizadas como el peligro, la amenaza (asignadas a ciertas personas o sectores), la afinidad o la indiferencia hacia algunos espacios, son prácticas que implican la incorporación de un conocimiento cotidiano, sentido común que, basado en unos estereotipos generalizados, contribuye a la configuración de un orden social en la ciudad. En este sentido, el estereotipo marca la relación con el "otro" desde la diferenciación, pero una diferenciación que consiste en un desconocimiento del "otro", en una reducción del "otro" a una sola de sus características reales, y en la legitimación de una forma de relacionarse con ese "otro" (Goffman, 1993, Bourdieu, 1998, Castillejo, 2000).

La diferenciación, a partir de los estereotipos, nos pone ante la tensión entre el ser y el parecer. En términos de Goffman se reconoce el carácter que le atribuimos a un individuo a través de una "identidad social virtual" y una "identidad real", es decir, de la apariencia y del ser, entendido este último como "la categoría y los atributos que, de hecho, según puede demostrarse, le pertenecen" (Goffman, 1993, 12). La tensión se representa entonces, entre una identidad virtual (parecer), y una identidad real (ser). En la ciudad el nivel de

6 Para ampliar este tema ver capítulo III "Geografía de la alteridad" del informe final de investigación Habitar la ciudad: Jóvenes y Distinciones Sociales en Medellín. INER-CODI, 2005. Universidad de Antioquia. la identidad virtual tiene un lugar privilegiado, en tanto allí hay una proliferación de diversos estilos de vida, grupos sociales y culturales que se cruzan constantemente sin detenerse en el conocimiento de los atributos que le pertenecen al ser; en este sentido el lugar del estereotipo adquiere un lugar central en las relaciones que se entablan con los "otros" en el contexto urbano.

Alejandro Castillejo (2000), al exponer la relación entre alteridad y espacio, plantea que "la alteridad se configura en relaciones de "cercanía y distancia cognitiva", "de intimidad y anonimato", "la imagen que configuramos del otro, a la distancia, está mediada por complicados procesos de tipificación: el otro no propiamente se revela, sino que se tipologiza -más concretamente, es a esto a lo que llamamos imagen o representación-" (Castillejo, 2000, 113).

Esta tipologización se da porque las relaciones que se entablan son a distancia y parten del desconocimiento, por lo cual esa limitada información que tenemos del otro, permite que se lo categorice a partir del estereotipo, convirtiendo el estereotipo en un imaginario generalizado. "La identidad del sujeto deriva de una clase a la que ha sido asignado. No los conocemos en el sentido que no hay cercanía cognitiva, pero sabemos de ellos. Los "conocemos" como tipos, como clases, no como personas individuales o narrativas particulares" (Castillejo, 2000), los conocemos desde su "identidad virtual" (Goffman, 1993).

Es en la relación con ese "otro" donde se configuran los tipos y estereotipos como una forma de aprehenderlo y explicar ese desconocimiento o distancia cognitiva, la cual representa también una distancia en el espacio social. Por un lado, el estereotipo parte de ese conocimiento en la distancia, es decir, un conocimiento desde la apariencia que no necesariamente habla de una característica "real" de ese "otro" (prejuicio). Por otro lado, existe otra forma de invisibilización, la reducción 
del "otro" a sólo una de las características de su identidad. En este sentido, Bourdieu nos habla de los "juicios de atribución" los cuales se definen como "unos actos de acusación, unos categoremas en su sentido original, y que, como la injuria, no quieren conocer más que una sola de las propiedades constitutivas de la identidad social de un individuo o de un grupo..." (Bourdieu, 1998, 486)

Tanto los juicios de atribución, que reducen el sujeto o el grupo a una sola de las características de su identidad, como los prejuicios o tipologizaciones que parten de la apariencia o la "identidad virtual" para definir al "otro", constituyen estrategias de diferenciación que se generalizan logrando asignar, tanto a grupos como a espacios, una identidad específica basada en el estereotipo. En este sentido, los individuos de determinada clase o barrio son identificados, entonces, desde un comportamiento predecible pues, por efectos de la incorporación del estereotipo "si vives en la periferia eres violento, o peor sicario y por lo tanto peligroso; si vives en El Poblado eres rico, levantado o narco...". Así, el comportamiento de la persona es reducido a las -supuestas- características del tipo. (Castillejo, 2000). Las conductas esperables de una clase no sólo configuran esa tipologización del otro, también configuran unas conductas de quien se guía por el estereotipo. En otras palabras, se configura una forma de actuar en relación con ese "otro" pues al suponer su conducta, yo anticipo la mía y la elaboro (Castillejo, 2000).

Es así como estudiar la configuración de estereotipos en la ciudad, y la manera como estos van definiendo unos órdenes geográficos que contribuyen en gran medida a reproducir y preservar formas de segregación en la ciudad se constituye en un campo importante para analizar las formas como los jóvenes se diferencian y se distinguen en sus prácticas de habitar la ciudad, para comprender cómo los espacios en la ciudad también se van configurando como unos "otros".
Sin embargo, para hablar de segregación es necesario remitirnos a otro nivel del estereotipo: el del estigma. Si bien en muchos casos estas palabras son utilizadas como sinónimos, proponemos diferenciarlos para analizar, desde allí la relación entre diferencias y desigualdades sociales. El estereotipo es un momento que antecede a la estigmatización, es decir, el estigma implica un estereotipo pero, ademá, hace de ese estereotipo un objeto de discriminación o segregación (Goffman, 1993).

Loic Wacquant en su trabajo los "parias urbanos" (2004), muestra cómo el espacio se instituye también como representación de la alteridad a través del estigma ("estigma territorial"), como "otro" extraño, lejano e inaprehensible. Por lo tanto, la estigmatización no sólo tiene efectos en la segregación de un grupo como una forma de ordenamiento del espacio, sino que también configura diferenciaciones internas.

Esto nos acerca al hecho de habitar en una zona periférica, o en el caso de Medellín, una zona identificada como "popular" donde confluyen representaciones paradójicas: peligro y violencia/ humildad y solidaridad. Como lo plantean algunos jóvenes que viven en barrios periféricos, en muchos casos ser de un determinado barrio ya es motivo de estigmatización, y más allá de eso "vivir en un sector estigmatizado de la ciudad significa una penalización en el mercado laboral" (Wacquant, 2004, 137) y en el acceso a otros espacios de la ciudad.

La reflexión en torno la configuración de estereotipos y estigmas pensados también desde lo espacial nos permite, entonces, conjugar la alteridad social con la alteridad espacial; comprender cómo un espacio físico, en tanto trasciende su condición material, puede incorporar y representar las características que les son asignadas a sus habitantes, es decir, el espacio también puede ser sujeto de las representaciones de la alteridad. De 
esta manera, las representaciones de los "otros" (sujetos) y los "otros" (espacios) son indisolubles a la hora de pensar los procesos de segregación y ordenamiento geográfico en la ciudad, a partir de los órdenes sociales cotidianos que interiorizamos en el transcurso de nuestras historias individuales y colectivas (Bourdieu, 1999).

Finalmente, como lo plantea Castillejo, "administrar un espacio es también administrar una representación de la alteridad, es configurar un imaginario en un proceso multiforme" (Castillejo, 2000, 130). Así, el espacio no es solamente administrado desde lo institucional, sino también desde nuestros órdenes cotidianos y nuestras formas de habitar la ciudad.

\section{LOS JÓVENES IMAGINAN SU CIUDAD}

La estrategia metodológica del proyecto se basó en una perspectiva etnográfica que se fundamentó en la consideración de los lugares concebidos, reconocidos y habitados cotidianamente dentro de la ciudad por los jóvenes con quienes trabajamos. Se utilizaron los métodos tradicionales de la disciplina antropológica, como son las entrevistas abiertas, conversaciones, observación directa (recorridos urbanos con los jóvenes) y talleres. Dentro de los talleres se combinaron varias técnicas de recolección de información: discusiones en grupo, trabajo con cartografía, elaboración de dibujos sobre la ciudad, narraciones de historias sobre la cotidianidad (relatos) y autobiografías.

La actividad de los relatos resultó fundamental. Para De Certeau, el relato constituye una práctica del espacio que pone de manifiesto las ideas y creencias que nos guían en nuestra experiencia de habitar la ciudad, es decir, desde el relato se autorizan o restringen, la mayoría de las veces, los andares en la ciudad (De Certeau,
2000). A su vez, el relato constituyó nuestro objeto de análisis, pues las discusiones colectivas y entrevistas individuales fueron las principales estrategias de indagación durante el trabajo de campo. Esto permitió que los mismos jóvenes se preguntaran por otros lugares de su ciudad y se interesaran no sólo en los lugares propios, sino también por aquellos estereotipados y en algunos casos estigmatizados. En este sentido, interrogar los estereotipos y estigmas se evidenció como un paso importante para propiciar lugares de convivencia y reconocimiento en la ciudad.

\section{Relatos de ciudad}

Los relatos e imágenes que aparecen a continuación hacen parte de los productos recolectados durante las diferentes actividades del taller. Dentro de ellas se encuentran la elaboración de una gráfica de la ciudad en general y la construcción de un relato descriptivo sobre un sector de la ciudad. Con la primera actividad se pretendía obtener los elementos que los jóvenes consideran más representativos de su ciudad y, a su vez, conocer las semejanzas y diferencias existentes en las percepciones de su ciudad.

Dentro de las representaciones que los jóvenes elaboraron encontramos cuatro grupos: Las que dan prioridad a los símbolos oficiales; Las que representan la ciudad desde los símbolos deportivos; Las que identifican a la ciudad como un espacio de la diversidad y el caos, y, finalmente, las que representan a la ciudad desde un espacio más local como el barrio o el sector. Además, dentro de todas esas representaciones de la ciudad encontramos una representación constante de una ciudad que se debate entre el caos y el progreso.

Símbolos oficiales. En este grupo aparece la constante de los símbolos paisas, las montañas, el edificio Coltejer, las flores, el metro, el metro cable, el cerro Nutibara, el aguardiente y las esculturas de Botero. En las explicaciones dadas por los jóvenes hay una fuerte referencia a la identidad 
paisa representada desde la pujanza, la alegría y el progreso. Los denominamos símbolos oficiales son aquellos dibujos cargados de las imágenes que Medellín proyecta de manera oficial hacia afuera. Este grupo referido a los símbolos oficiales de la ciudad fue una constante en la representación de la ciudad que hicieron los jóvenes del colegio Isolda. En este conjunto aparecen, además, representaciones que no se quedan en los símbolos estereotípicos de la ciudad sino que se apropian de unos nuevos símbolos que también podríamos llamar oficiales, o elementos de una nueva imagen de la ciudad como el parque de Los Deseos, el parque de Los Pies Descalzos y la plazoleta de Las Luces.

\section{DIM}

Esta representación es interesante para entender cómo, a partir de un elemento identitario, el fútbol o su equipo, se puede definir la idea de la ciudad. Para estos "hinchas" del DIM su ciudad ideal sería un Medellín con la forma del escudo del equipo, pero en esta ciudad también hay fuertes distinciones como la que se impone con el "verde", el cual sólo en algunos momentos cabe en esa representación. En este mapa-escudo de Medellín llama la atención que el barrio La Cruz se sigue representando como un lugar periférico, uno de los extremos de la representación.

La descripción que los jóvenes dieron de su dibujo nos remite a otros elementos de distinción.

Es que el Medellín es muy poderoso...... en cambio el nacional, es de la montaña!...

Medellín es el ciudadano, en cambio el nacional es un desplazado de la montaña... entonces viene a que le demos alojamiento acá, en nuestro territorio... entonces nosotros lo ubicamos.... (Jóvenes de La Honda).

Esta explicación pone de manifiesto, no sólo la identificación de la ciudad desde el fútbol, sino aspectos de la distinción que estos jóvenes han experimentado en la ciudad, dado que la mayoría de ellos vienen desplazados de zonas rurales. La metáfora de los equipos que se diferencian y representan la ciudad, para referirse a otra diferenciación ciudadano/desplazado, es aquí una fuerte imagen que pone de relieve una experiencia que estos jóvenes han vivido como habitantes de la ciudad: la experiencia de la marginación.

Diversidad - Caos. Este grupo de imágenes representa la idea de ciudad como un caos lleno de diferencias y desigualdades irreconciliables, que luchan entre ellas como en un campo de batalla. Este tipo de representación sólo fue identificada en los trabajos de los jóvenes del INEM. Un aspecto a resaltar de este grupo de imágenes es que hacen un fuerte énfasis en las diferencias generacionales, es decir, el caos se representa principalmente como consecuencia de las formas de vida de los jóvenes. Así, de la imagen "las culturas de Medellín", llama la atención, sobre todo, que en ésta los jóvenes reafirman el estereotipo, incluso desde su misma posición de jóvenes, de que el caos y el desorden son propios de este grupo generacional de la ciudad.

\section{Las culturas de Medellín}

Todo esto busca reflejar todas las culturas de Medellín. La Medellín atrasada, la Medellín que ya no quiere progresar, la Medellín plagada de tecnología, de sexo, la Medellín plagada de tantas cosas que ya no sirven, de droga, de dinero.... de tantas cosas. En el medio buscamos como reflejar algunas poquitas personas que tratan como de superarse, que tratan de subir, que tratan de mejorar, y gente que trata de unírseles pero que no se puede precisamente por toda esta sociedad. También se busca mostrar la Medellín bonita, la Medellín que fue linda, o que es linda, la de la naturaleza, la de la tacita de plata que todos conocemos, tantas cosas, la 
de la eterna primavera, y cómo la misma cultura pobre, digámoslo así, de Medellín ha dañado todo esto, mire lo que es el río Medellín.

No cultura pobre no... o sea es que muchas culturas o muchas cosas que hacen de Medellín esa Medellín mala, muchos grupitos que miran feo, muchos grupitos que por allá, que hacen mal, que roban. Es como una forma de contaminación, que lo miren a uno feo, que lo traten como que lo aíslen, como que no se arrimen, se lo gozan.

La mitad es como la minoría, de diez personas una se revela, una quiere leer, una se mete con las artes, una quiere progresar" (Jóvenes del INEM).

La ciudad desde el entorno cercano. En este grupo de imágenes se concentran principalmente las elaboradas por los jóvenes del barrio La Honda, del colegio "Gente Unida Luz de Oriente". Estas imágenes nos remiten a una perspectiva que desde lo propio mira la ciudad, es entonces, la ciudad desde el entorno cercano, representaciones que, a su vez, juegan con el sentido de la periferia y del centro.

\section{La ciudad del Corazón}

Esta imagen pone de relieve los lugares a los cuales quien la dibuja se siente vinculada, es decir, aquí la ciudad es el entorno cercano y los espacios apropiados. La frontera de esta ciudad del corazón transforma las ideas de centro y periferia. Así, se identifica el sector del Centro de Medellín como un sector que se ubica por fuera de esa ciudad del corazón, es decir, como un elemento periférico, fuera de su centro, de su corazón. Mientras que el barrio La Honda, reconocido como un barrio periférico de la ciudad, es representado en este dibujo como el centro de la ciudad del corazón.
En estas diferentes representaciones de Medellín, encontramos una ciudad que se debate entre la conservación de una imagen de ciudad pujante y símbolo del progreso, donde aparecen la alegría paisa y el desarrollo como imaginarios fuertes, y una Medellín que, desbordada en sus fronteras, alberga tanta diversidad que es difícil encontrar puntos de encuentro y convivencia. Se representa también la Medellín caótica, violenta y con pocas oportunidades, donde la perspectiva planteada por los jóvenes para fugarse de ese caos, sólo es vista en el ámbito individual en actividades como la lectura, la música, el arte. Son, pues, dos imágenes que generan un fuerte contraste y que evidencian lo que podría considerarse como dos imaginarios fuertes de ciudad: el primero, alimentado desde una historia de ciudad industrial desarrollada, y el segundo, que representa el caos, alimentado desde la intensificación de la violencia en el contexto urbano en el marco del narcotráfico (Villa, Sánchez, Jaramillo, 2003). Estas dos representaciones paradójicas, al ser interiorizadas en el transcurso de su historia como habitantes de esta ciudad, conviven en ella y son reproducidas en la historia colectiva.

En este punto vale la pena hacer una reflexión sobre la asociación Medellín - Violencia. Esta imagen de ciudad que, como hemos dicho, se ha convertido ya en un estereotipo, aparece en los relatos de los jóvenes. Sin embargo, es una relación que se presenta como lejana en el tiempo (es cosa del pasado) todos recuerdan aspectos de su niñez a finales de los años 80 y en los 90 , en relación con una ciudad marcada por la guerra y el narcotráfico. Por otra parte, esos recuerdos aparecen borrosos, y en sus relatos la violencia aparece asociada a otros aspectos. Se evidencia, pues, una constante en el cambio de lenguaje y de mirada: ya no hay tantas historias de violencia 
para narrar la ciudad, y el caos que presentan se sustenta en otros elementos como la exclusión, la delincuencia, el hambre y la pobreza. Ya no se trata de los jóvenes hablando de la muerte (Blair, 2005), los sicarios o integrantes de bandas, etc., sino que aparece una imagen más asociada al peligro que a la violencia. Se cuenta más la ciudad desde otros referentes.

Sin embargo, la idea de Medellín como una ciudad violenta pervive en la memoria. Esto se expresa en los constantes imaginarios de miedo (Villa, Sánchez, Jaramillo, 2003) y peligro con los que se asocian diferentes lugares de la ciudad. Esto influye también en que se reconfigure un poco la idea de los lugares estigmatizados como peligrosos, es decir, se identifican nuevos lugares como peligrosos. En esa construcción del miedo, influyen de manera importante el sector donde se habita, el desconocimiento del lugar al que se le asigna el estereotipo de peligro y la forma como los medios de comunicación informan sobre los acontecimientos que han marcado a la ciudad.

Medellín, con un "pasado" violento, marcó la forma de habitarla y de pensarla: una Medellín de víctimas convertidas en héroes-mártires de una época y victimarios exotizados. Una violencia "pasada" que posiblemente oculta nuevas formas de violencia. En este trabajo encontramos una memoria de esta época de guerra, que resignifica la ciudad desde otras lógicas o trata de retomar discursos como el de la Medellín pujante y alegre. Pero si bien la historia de la Medellín violenta ha cambiado, se ha transformado, no podemos insertarnos ciegamente en un discurso que proclama el fin de la violencia, sólo porque las estadísticas ya no horrorizan. Es necesario cuestionar esta tendencia, pues en muchos casos la calma, que se intenta instituir mediante el discurso del fin de la violencia, lo que hace es silenciar y legitimar otras violencias que continúan presentes en la ciudad. ¿Cuáles son esas violencias ocultas y legitimadas bajo paradigmas de seguridad? Esto sería un asunto interesante de abordar en la ciudad; la transformación de la narrativa sobre la violencia que hace memoria de un pasado y silencia otras violencias que se cubren bajo el velo de discursos como "la calma vuelve a la ciudad", "tres años después del despertar en la 13", ' etc.

\section{Relatos de barrios}

En este nivel nos acercamos ya a la escala barrial. En la actividad de construir un relato descriptivo de un sector o barrio de la ciudad los jóvenes expresaron una mayor afinidad, y, aquí, el nivel de detalle para describir ciertos contextos fue de una riqueza excepcional. Además, el desarrollo de esta actividad fue un momento donde los jóvenes realizaron una ruptura con el discurso de la tolerancia a la diversidad, el cual había predominado en los primeros talleres. En esta actividad desaparece de alguna manera el temor por emitir juicios acerca de ciertos lugares en un contexto público como lo era el aula de clases y más aún el espacio del taller, coordinado por personas ajenas a su contexto.

Al analizar estos relatos, surgió la preocupación por la fabulación y la ficción que muchos de ellos contienen. No obstante, considerábamos que precisamente la actividad de describir diferentes barrios pretendía desentrañar esas imágenes que, si bien no son siempre "reales", parten de las ideas que poseemos de ciertos espacios en la ciudad. En este sentido lo que plantea Armando Silva (1992) nos da luces para no desechar las descripciones "fabuladas", sino más bien considerarlas también como parte de lo "real de una ciudad". Dice Silva: "Podemos decir

7 Titular El Colombiano, Noviembre 6 de 2005. En el artículo titulado de esta manera, se señala el gran cambio en la comuna 13 después de la operación Orión, donde "gracias" a las acciones de las fuerzas militares se logró pasar de una violencia intensa, miedo, muertes, secuestros y desplazamiento intraurbano a la tranquilidad y alegría de la cual disfrutan hoy sus habitantes. Tomado de: www.elcolombiano. com Noviembre 6 de 2005. 
que lo real de una ciudad no es sólo su economía, su planificación física o sus conflictos sociales, sino también las imágenes imaginadas construidas a partir de tales fenómenos, y también las imaginaciones construidas por fuera de ellos, como ejercicio fabulatorio, en calidad de representación de sus espacios y de sus escrituras" (Silva, 1992; p. 134).

Si bien se realizaron descripciones de diferentes barrios de la ciudad, aquí presentaremos una selección de relatos sobre algunos de los barrios reconocidos como populares en la ciudad, y un sector presentado en los mismos relatos como su opuesto, El Poblado.

\section{Santa Cruz y los Populares}

Había una vez unos indios que usaban taparrabos y vivían en el valle de Aburrá, era una ciudad muy pequeña, constituida por cuatro barrios: Aranjuez, Santa cruz, Popular 1 y popular 2, los cuales anteriormente tenían varias bandas delincuenciales (pero ya con pantalones), de las cuales resaltamos los del "Chispero", los de "la Laguna", los de "la Torre", los de "la Terraza", quienes en este momento son controlados por "don Berna" ${ }^{8}$. La gente que habita estos barrios es generalmente de bajos recursos, su organización social es generalmente por cuadras. En esta ciudad siempre encontramos dos o más tiendas, atendidas por un "don Juan", "don Pedro", "doña Margarita" o "don German" y no falta la peluquería de los travestís "Coqui", "Luz", "San Angelo" y "Caprimoda". Se ven muchas modas populares, pasaron del oro al plástico (en sus accesorios). No faltan los testigos de Jehová desesperados por cambiarnos nuestras formas de pensar, tampoco falta el señor que vende mazamorra y pasa por todas las calles a las 6:00 am gritando "mazamorra" con horrible acento, no faltan las señoras chismosas que asisten fielmente a la misa del domin-

8 Ex Jefe Paramilitar de Medellín. go y critican la forma de vestir y de actuar de la otra gente. A la salida de la iglesia la venta de empanadas "del papa" (porque no tienen papa). (Jóvenes del INEM)

\section{Doce de Octubre}

Este lugar se ve muy poblado, es popular, la gente que vive en este lugar es humilde, de bajos recursos, es de difícil acceso, sabemos que es un barrio conflictivo, su vocabulario es "pesado". Las fiestas se hacen en las cuadras, como sancochado, la marranada de diciembre, las frijoladas de año nuevo, las jugadas de fútbol, las "polas" en la tienda de la esquina, las panaderías. Su música reguetón, porros, salsa, rap, vallenatos, se ve mucho los carros de chuzos a quinientos pesos.

La gente se viste [asi]: las mujeres con faldas altas y camisas escotadas, los fines de semana las pintas mejores. En diciembre el estrén del 24 y el 31.

Trabajan como empleados y dueños de negocios pequeños. Ellos creen mucho en Dios y se encomiendan a Dios y a las vírgenes. Creen en sus amigos ya que tienen barras (grupos de amigos) en la lealtad. Comen cotidianamente granos, agua panela, pan de leche, entre otras. Uno que otro día se dan gustos, depende de la fecha (fechas especiales). (Jóvenes del Isolda)

\section{La Cruz}

Es un lugar agradable aquí llegan las busetas y también hay una iglesia donde hacen misa los Domingos a las 12:00 pm y 5: 00 pm también los sábados. Atrás de la iglesia hay una cancha, hay teléfonos públicos y muchos almacenes, discotecas, cantinas, restaurantes. Hay un lugar donde se deposita la basura los martes y viernes. Subiendo para la primavera hay una ludoteca donde hay clases de diseño, artesanía y baile los martes y jueves de 2 a 4 pm. El padre muchas veces dona cosas. En la primavera hay billares, cantinas, tiendas 
y cancha donde los fines de semana las personas hacen deportes, bailan y toman. Arriba de la primavera queda el colegio donde se estudia desde el grado preescolar hasta el grado $9^{\circ}$ y las clases empiezan a las 6:30 am hasta las 12:30 pm y de 12:30 pm hasta las 5:30 pm, aquí se aprende mucho todos los días. Hay unas casas más pobres que otras, unas familias más mal económicamente y familias con más problemas que otras y son personas que les agrada ayudar a las personas más necesitadas (Jóvenes de la Honda, colegio Gente Unida).

Vemos en el primer relato un elemento interesante asociado al tiempo y su relación con el espacio. Así, los barrios descritos en el primer relato no sólo están lejanos en el espacio geográfico de la ciudad, sino también lejanos en el tiempo, es decir, atrasados. El pasado sigue jugando un papel central en algunas de las características señaladas. Es el caso de la existencia de bandas delincuenciales, asociadas a un pasado que, en el presente, se transforma en otra realidad, descrita como el monopolio del poder en manos de los grupos paramilitares. Dos elementos entonces se evidencian en estos relatos como característicos de dichos lugares: una lejanía respecto al centro de la ciudad, lejanía en el tiempo y el espacio y la existencia de amenaza, peligro y violencia que, si bien aparece transformada, continúa como un elemento presente.

Por otra parte, en los relatos se evidencia el componente económico definido desde el acceso a los recursos materiales, es decir, poseer o no recursos económicos. Este es un aspecto bien interesante que aparece en todos los relatos y a pesar de parecer un elemento muy evidente para definir un barrio popular, allí se ponen de relieve ciertas formas del discurso que contribuyen a definir qué es ser pobre o de bajos recursos. Aquí se perfila entonces la palabra "humilde" como un adjetivo central para definir a las personas pobres o de bajos recursos. En el relato construido por los jóvenes del Isolda, este adjetivo aparece como una forma de matizar la apreciación "es gente de bajos recursos", como un eufemismo, mientras que en el relato de los jóvenes del INEM, ese aspecto económico es caracterizado de manera directa.

El papel del eufemismo para hacer este tipo de descripciones o definiciones del "otro" tiene un lugar importante sobre todo en el discurso público, ante "otros" desconocidos, que fue el discurso al que pudimos acceder en este trabajo. El eufemismo aparece entonces como un aspecto recurrente, sobre todo en los relatos de los jóvenes del colegio Isolda. Estos usan palabras que tratan de enmascarar o menguar lo que quieren decir, por ejemplo, "su vocabulario es "pesado", o "son barrios "conflictivos".

Por su parte, los jóvenes de La Honda también usan el adjetivo "humilde" además del adjetivo "sencillos" para referirse a los habitantes de estos barrios. Al contrario de lo que vimos con los relatos del colegio Isolda, este grupo no iguala la categoría "humilde" con la idea de gente de "bajos recursos económicos"; los jóvenes de La Honda en sus descripciones hablan de las personas como gente humilde pero que "no tienen muchos problemas económicos".

Otro de los aspectos relevantes de los relatos es la recurrencia de diversos elementos del paisaje geográfico. Se presenta, así, un paisaje de barrio que define y es definido a su vez por la organización social de las personas que allí habitan. En esta descripción se evidencian elementos como la tienda, -un eje central de la vida de barrio-, la cuadra, y los personajes de barrio: tendero, peluquero, mazamorrero, señora chismosa que va a la iglesia, testigos de Jehová, etc... El mobiliario y el paisaje, que caracterizan el barrio, son igualmente centrales en los relatos de los jóvenes de La Honda; especialmente cuando se trata de caracterizar su barrio. Estos relatos hacen énfasis y recalcan la presencia de cierta infraestructura. Esta 
característica del relato, obedece a la intención de contrarrestar la imagen de una zona alejada de la ciudad, precaria y calificada como "tugurio" donde no es agradable vivir. En la descripción que los jóvenes de La Honda hacen tratan de transformar de manera evidente esta idea. Reconocen su barrio, igualmente como un barrio con dificultades, sin embargo, siempre ponen de relieve la solidaridad como un valor de todos sus habitantes, lo cual es un elemento central de la vida de barrio que hace la convivencia mucho más amable.

Pasamos ahora a otro lugar, cargado igualmente de estereotipos, y lleno de imágenes sobre la "elite", "los ricos", "los narcos": El Poblado.

\section{El Poblado}

Gran parte de las personas que habitan en el Poblado son familias acomodadas. La mayoría trabajan en oficinas o en empresas propias, se divierten en la zona rosa de El Poblado, Las Palmas, La 33. Salen a comer frecuentemente a centros comerciales, a McDonalds restaurantes como Il Forno, etc. Las casas son grandes, ahora son los espacios más reducidos, hay unidades cerradas de edificios altos. Por lo general todos tienen carros o motos, el transporte público es muy bueno porque llega hasta casi todos los rincones. Escuchan música tropical, reguetón, Vallenato, pero no todos, también electrónica, rock, punk, metal. (Jóvenes del colegio Isolda)

\section{El Poblado}

Es una ciudad fundada en 1821, ahora es lo que llamamos el sector de los ricos, en este hay varios sectores, entre los cuales hay un sector acomodado, que es como la parte menos favorecida, otro es el sector comercial donde están ubicados los centros comerciales, las discotecas, bares, hoteles, restaurantes, etc. Y la parte alta que es un sector muy organizado. Es una ciudad muy educada, donde hay mucha cultura. Hay varias estaciones del metro y comprende desde los Almendros hasta el Perpetuo Socorro. Esta es la zona más visitada, el parque Lleras, que es donde están los mejores centros comerciales y bares de la ciudad. En este lugar van muchas personas a divertirse y a pasarla bien, también a hacer compras en los centros comerciales. (Jóvenes del INEM)

\section{El Poblado}

Las calles de El Poblado comúnmente son muy limpias y tienen muchas praderas, tiene unidades cerradas y hay muchas mascotas. La gente tiene muy buenos autos, las personas de allí no van a La Minorista, van a los supermercados como el Ley, el Éxito, visitan almacenes de ropa de marca. Es un lugar que tiene que tener mucha vigilancia.

Las personas que habitan allí visten muy bien con ropa de marca, aunque hay personas que son muy sencillas aunque tengan mucha plata. Hay personas que tienen sus propios negocios, otros que trabajan en empresas. En ese lugar las comidas son menos comunes que en este barrio (quieren decir que comen cosas raras) y tienen sus propios horarios de comida. (Jóvenes del colegio Gente Unida).

En el mismo orden que ubicamos el adjetivo "humilde", para el caso de las descripciones de los barrios populares, podríamos ubicar para El Poblado el adjetivo "acomodado". Éste opera, entonces, como una manera de referirse a las per sonas de estratos socio económicos altos. Pero, al mismo tiempo, este adjetivo posee algunas acepciones diferentes en los relatos presentados. En el caso del primer relato "acomodado" es un sinónimo de "rico" o de persona con recursos económicos altos. Por su parte, el caso del segun do relato que evidencia la existencia de diversos sectores en el Poblado, describe el sector donde están las personas "acomodadas" como el sector "menos favorecido", en comparación a lo que ellos denominan "ricos", es decir, en el segundo 
relato "rico" y "acomodado" tienen significados diferentes. En todos los relatos aparece la propiedad privada como un elemento importante en las descripciones: carros propios, casas propias, empresas propias. Un aspecto central de estas descripciones, que no aparecen en las de los otros barrios, es que entran en escena los edificios y urbanizaciones cerradas. El Poblado es visto entonces como un lugar muy vigilado, donde la gente no habita la calle sino sus urbanizaciones o sus espacios privados.

En el relato de los jóvenes del INEM, la propiedad es asociada al comercio, lo que caracteriza el Poblado como un lugar donde se escenifica el consumo desde muchos niveles, shopping, rumba, turismo etc., por lo tanto, este barrio es visto también como un lugar para visitar, para "ir a divertirse". En el relato de los jóvenes de La Honda aparece también el consumo, pero más desde la caracterización de donde van a consumir quienes habitan en El Poblado y no El Poblado como un lugar de consumo. En este sentido es interesante la diferenciación que establecen entre la plaza de mercado minorista y almacenes como el Éxito o el Ley, donde ellos -la gente de El Poblado- van a mercar. Este elemento es importante en tanto la plaza de mercado Minorista es un lugar muy cotidiano para la gente de La Honda y La Cruz. La mayoría de los habitantes de La Honda van allí a comprar sus alimentos y también es en la Minorista donde las personas del barrio, principalmente los desplazados, van a hacer lo que denominan "el recorrido", el cual consiste en ir a conseguir, en los diferentes puestos de mercado, alimento para sus familias.

El relato de los jóvenes de La Honda hace énfasis en la descripción del paisaje, donde llama la atención la palabra "praderas", usada seguramente para referirse a las zonas verdes. Describen, así, unas praderas acompañadas, a su vez, de grandes edificios. Vemos cómo en esa tipología del relato, que describe el lugar desde lo que hay allí, cambia considerablemente en los tres ejemplos. En el primero -el de los jóvenes del Isolda- el conocimiento del lugar se hace explícito en el señalamiento de lugares concretos; este aspecto va cambiando a medida que hay un alejamiento tanto en el espacio físico como en el espacio social. Así, en el segundo relato -el de los jóvenes del INEM- sólo se hace referencia a un espacio concreto, además, muy conocido, el parque Lleras y, finalmente, quienes están más alejados de la gente de El Poblado, en este caso los jóvenes de La Honda, son los que no ponen ninguna referencia a un lugar específico en este sector.

Finalmente, se pueden evidenciar algunas constantes en las representaciones de los barrios, por parte de los diferentes grupos; entre ellas, encontramos la relación entre capital económico y valores, la paradoja de los barrios populares y la apropiación del estigma.

La relación entre capital económico y valores sociales es presentada en muchos relatos como una ecuación donde la variable de los valores es inversamente proporcional a la otra. Así, generalmente, se asocian los sectores de mayor estrato económico como "gente de pocos valores" y, por el contrario, los sectores identificados como de escasos recursos económicos se identifican con "gente con valores, muy buena, sencilla y humilde". Esta práctica nos permite, a su vez, plantear que los estereotipos y estigmas no son solamente comprensibles desde una mirada jerárquica que busca entender las relaciones entre dominados y dominantes. Se trata más bien de comprender cómo los estereotipos fundamentan la representación del "otro" a partir de su desconocimiento y son generados en múltiples direcciones. Esa primera relación nos lleva a otra de las constantes que se les atribuyen a los barrios populares. Así, lo popular y específicamente los barrios populares son identificados con la nobleza, humildad, solidaridad y al mismo tiempo con el peligro, la 
violencia y la inseguridad. En el siguiente relato se puede ver esa representación paradójica:

La primera vez que yo fui a Popular, que yo ya conozco Popular, no, yo era emocionado viendo las casas, viendo todo el mundo no sé me despierta una emoción.

\section{M: ¿te sentías como en tu espacio?}

Sí, me despierta pues un... pues no es mi espacio, pues que yo diga que yo me identifico ahí no, pues porque muy maluco uno vivir por allá, pero me encanta, me encanta ir a todas partes. Pero lo más bacano en sí de estos barrios es como la nobleza que se ve en esos barrios, se pueden ver sí muchos... al ser populares porque con ese nombre los conocemos, son barrios que ven mucho los atracadores, los matones, los violadores más que todo, pues pero en sí a pesar de toda la violencia que se viven en estos barrios pues hay como una especie de nobleza entre la gente que vive ahí que pues es como un ambiente hasta bacano, entonces sí, uno se siente pues bien allá, no se siente como en este caso como el Poblado que uno se siente rechazado como de otra parte. Mal, se siente muy mal. (Joven del INEM)

Así, los barrios populares son objeto de múltiples representaciones, no todas asociadas a la violencia. Sin embargo, lo que encontramos en esas representaciones es, sobre todo, un estereotipo que se fundamenta en el desconocimiento y aislamiento que caracterizan la relación de la ciudad con estos barrios. Este aspecto nos remite, finalmente, a la última constante, y es la de la apropiación del estigma. Lo que encontramos principalmente en relación con los barrios populares y sus estereotipos es que quienes luchan por su visibilización y reconocimiento, en muchos casos, lo hacen desde la misma apropiación del estigma y su reproducción. Es decir, se continúa propiciando un conocimiento, que si bien puede basarse en características reales de estos espacios y sus habitantes, los reduce sólo a una de ellas, por ejemplo, a la violencia, la característica desde donde más han sido contados estos sectores en Medellín. No se trata, entonces, de desconocer que allí existen unas problemáticas reales asociadas a la violencia y el conflicto, sino más bien, de llamar la atención sobre las maneras como se reproducen los estigmas y nos apropiamos de ellos al encerrarnos en unos discursos que, constantemente, están desconociendo la diversidad de características que, además, componen un barrio o un sector popular.

En este mismo sentido, los habitantes de un determinado espacio terminan incorporando el estigma con el que éste es reconocido y autoexcluyéndose de otros espacios donde se cree serían juzgados por pertenecer a determinado barrio o por poseer determinada apariencia. Una consecuencia de esa apropiación del estigma es la ruptura de lazos sociales en el interior de un grupo o sector (Wacquant, 2001).

Vivo en un barrio muy popular, pues vivo en Manrique pero no mantengo ahí, o sea, tengo mi propio mundo afuera de eso y no me cierro que porque vivo en Manrique tengo que ser la mas ñarria, la más chirrete, la que no conoce...

M: ¿y relacionas esos adjetivos de ñarria, chirrete con tu barrio?

$\mathrm{Si}$, por ejemplo yo siempre he vivido en Manrique y ahí se ve mucho eso, o sea la gente más popular es la menos educada, es la que se pega de un solo género.

Es evidente, entonces, que las estrategias de distinción no sólo operan hacia fuera de un barrio o una zona, también en el interior del barrio estos jóvenes se diferencian y, por lo tanto, se distinguen de los "otros" que, a su vez, son sus vecinos. Esto es visible en el caso de los jóvenes que se sienten 
excluidos en el interior de sus propios contextos por ser jóvenes, por vestirse de cierta manera, o por escuchar cierto tipo de música, etc.

En las imágenes y relatos que describimos se evidencian las formas como la ciudad está conformada por múltiples ciudades. Diversas versiones de ella, que cohabitan y se reconstruyen constantemente, en medio de una tensión entre la alteridad y la identidad; entre unos "otros" cercanos que se insertan en nuestro horizonte de conocimiento, y unos "otros" extraños, que conocemos a partir de la apariencia y el estereotipo. En esa tensión, entre el habitar unos espacios y evitar otros, se está poniendo de relieve cómo el espacio mismo, incorpora las representaciones de la alteridad que circulan, cotidianamente, en la ciudad y se configura también como un "otro".

\section{CONCLUSIONES}

El proyecto indagó por las distinciones sociales y sobre las estrategias de distinción que sustentan categorizaciones asociadas a las formas de habitar la ciudad, en su mayoría incorporadas y naturalizadas, que llevan a definir al "otro" como pobre, burgués o peligroso y cómo esos elementos son asociados a los lugares que los "otros" habitan. Esto nos exigió ir más allá del simple hecho de reconocer qué lugares se visitan y qué lugares se evitan, y más bien nos llevó a indagar por las representaciones, los estereotipos y estigmas que se construyen sobre los espacios y los "otros" que los habitan, para lograr comprender los criterios de distinción que nutren las segregaciones urbanas.

Como lo anunciamos desde la introducción el enfoque que empleamos entiende las diferencias desde su trasfondo político para comprender cómo esa diversidad, -que cohabita en la ciudad-, enfrenta, principalmente, desencuentros, exclusiones, segregaciones, en suma desigualdades (Canclini, 2004).
Los estigmas territoriales encarnados en los discursos de los jóvenes ejemplifican, de manera interesante, esa relación entre diferencias y desigualdades; nos muestran, entonces, cómo es necesario cuestionar esos órdenes "naturalizados" donde están incluidos estereotipos y estigmas, para empezar a re-conocer al "otro", antes que exotizar su diferencia, mientras se le sigue alejando y excluyendo dentro del espacio social.

En este proyecto encontramos que los jóvenes también están insertos en una lucha por configurar sus identidades particulares y diferenciarse de los "otros". En este sentido es importante pensar que las estrategias de distinción hacen parte de la dinámica social de todos los grupos, incluso aquellos "normalizados" y no solamente de los que las ciencias sociales han definido como "diferentes". Lo que queremos reafirmar es que la alteridad no es necesariamente lejana y que tampoco está expresada en grupos delimitados de manera clara. En otras palabras, es importante cuestionar una mirada, tal vez propiciada desde la antropología, que ubica a los "otros" en el marco de unos límites precisos y define la relaciones entre alteridades de manera cerrada, es decir, se piensa cómo un grupo (pretendidamente homogéneo), piensa a su "otro" grupo de manera unívoca: de indios a blancos, de jóvenes a adultos, de pobres a ricos, etc.

Después de trabajar con diferentes grupos, vemos, como un campo importante a explorar, cómo, en este caso, los jóvenes, retoman sus propios fines, en busca de reivindicaciones sociales y luchas para transformar el lugar en el que el orden social los ha ubicado.

Finalmente, la experiencia de establecer un diálogo con los jóvenes sobre la ciudad y sus diversas versiones nos permitió interrogar diferentes estereotipos que circulan en la ciudad, desde sus experiencias cotidianas, logrando que los mismos jóvenes se 
preguntaran por otros lugares de su ciudad y se interesaran no sólo en los lugares propios, sino también por aquellos estereotipados y en algunos casos estigmatizados. En este sentido, interrogar los estereotipos y estigmas se evidenció como un paso importante para propiciar lugares de convivencia y reconocimiento en la ciudad.

\section{REFERENCIAS BIBLIOGRÁFICAS}

Blair, E. "Muertes violentas: la teatralización del exceso". Universidad de Antioquia, 2005.

Bourdieu, P. (1998). La distinción. Madrid: Editorial Tauros.

. (1999a). Razones prácticas: Sobre la teoría de la acción. Barcelona: Editorial Anagrama.

(1999b). La miseria del mundo. Buenos Aires: Fondo de Cultura Económica.

Bourdieu P. y Loïc J.D. Wacquant. (1995). Respuestas. Por una Antropología reflexiva. México: Editorial Grijalbo.

Castillejo A. (2000). Poética de lo Otro. Para una antropología de la guerra y el exilio. Bogotá: ICANH-Colciencias.

Cignoli A. (1997). "Ciudad y territorialidad. Modos de abordar la cuestión". En: Política e Trabalho, No. 13. Setembro, Brasil.

De Certeau, M. (2000). La invención de lo cotidiano. I Las artes de hacer. México: Universidad Iberoamericana, Instituto Tecnológico y de Estudios Superiores de Occidente.

Echeverría, M. Clara y Analida R.. (2000). Ciudad de territorialidades. Polémicas de Medellín. Medellín: Universidad Nacional.

Delgado, M. (1999). El animal público. España: Anagrama.

Elias N. (1998). "Ensayo teórico sobre las relaciones entre establecidos y marginados". En: La civilización de los padres y otros ensayos. Santa Fe de Bogotá: Grupo Editorial Norma y Editorial Universidad Nacional.

Escobar, J. C. (2000). Lo imaginario. Entre las ciencias sociales y la historia. Medellín: Fondo Editorial Universidad EAFIT.

Ferrándiz, F. y Carles F., (Eds). (2005). Jóvenes sin tregua. Culturas y políticas de la violencia. España: Anthropos.

Garcés Montoya, Á. (2005). Nos-otros los jóvenes. Polisemias de las culturas y los territorios musicales en Medellín. Medellín: Sello Editorial Universidad de Medellín.

García Canclini, N. (2004). "Diferentes, desiguales y desconectados. Mapas de la Interculturalidad". Buenos Aires: Gedisa.

Goffman, E. (1993). "Estigma. La identidad deteriorada". Buenos Aires: Amorrortu Editores.

Krotz, E. (1994). "Alteridad y pregunta antropológica", En: Revista Alteridades, No 4, México.

Kuusisto, A. (1999). "Politics of place and resistance: the case of Northern Ireland". En: Journal, Nordia Geographical Publications, NGP, Yearbook, Volume 28, No.2. 
Naranjo, G. y Villa, M. I. (1997). Entre luces y sombras. Espacio y políticas urbanas. Medellín: Corporación Región.

Pardo, J. L. (1992). Las formas de la exterioridad. Valencia: Editorial Pre-Textos.

Pintos J. L., (1993). "Orden Social e Imaginarios Sociales". [En línea]: http://web.usc.es/ jlpintos/articulos/ ordensocial.htm

Quiceno, N. (2005). Habitar la ciudad: jóvenes y distinciones sociales en Medellín. Informe de investigación, CODI-INER, Universidad de Antioquia, inédito.

Santos, M. (2000). La naturaleza del espacio. Barcelona. Editorial Ariel.

Silva, A. (2000). Imaginarios urbanos: Bogotá y Sao Paulo. Cultura y comunicación urbana en América Latina. Bogotá: Tercer Mundo Editores.

Senett, R. (1997). Carne y piedra. El cuerpo y la ciudad en la civilización occidental. España: Alianza Editorial.

Villa, M. I., Sánchez, L. A. y Jaramillo, A. M.. (2003). Los rostros del miedo. Investigación sobre los miedos sociales urbanos Medellín: Corporación Región.

Villa, M. I., (Ed.). .2002). El miedo. Reflexiones sobre su dimensión social y cultural. Medellín: Corporación Región.

Wacquant, L.. (2001). Parias urbanos. Marginalidad en la ciudad a comienzos de milenio. Buenos Aires: Manantial. 